\title{
Article \\ Comparison of Cytomegalovirus-Specific Immune Cell Response to Proteins versus Peptides Using an IFN- $\gamma$ ELISpot Assay after Hematopoietic Stem Cell Transplantation
}

\author{
Eva Wagner-Drouet ${ }^{1}$, Daniel Teschner ${ }^{1}$, Christine Wolschke ${ }^{2}$, Kerstin Schäfer-Eckart ${ }^{3}$, Johannes Gärtner ${ }^{3}$, \\ Stephan Mielke ${ }^{4,5}$, Martin Schreder ${ }^{4, \dagger}{ }^{4}$ Guido Kobbe ${ }^{6}$, Inken Hilgendorf ${ }^{7} \mathbb{D}$, Stefan Klein ${ }^{8}$, Mareike Verbeek ${ }^{9}$, \\ Markus Ditschkowski ${ }^{10}$, Martina Koch ${ }^{11, \ddagger(1)}$, Monika Lindemann ${ }^{12}{ }^{\mathbb{D}}$, Traudel Schmidt ${ }^{13}$, Anne Rascle ${ }^{13}$, \\ Sascha Barabas ${ }^{13}$, Ludwig Deml ${ }^{13}$, Ralf Wagner ${ }^{13,14, *}$ and Daniel Wolff ${ }^{15, * \text { (i) }}$
}

1 Department of Hematology, Medical Oncology, and Pneumology, University Medical Center of the Johannes Gutenberg University, 55131 Mainz, Germany; eva.wagner@unimedizin-mainz.de (E.W.-D.); daniel.teschner@unimedizin-mainz.de (D.T.)

2 Department of Stem Cell Transplantation, University Medical Center Hamburg-Eppendorf, 20246 Eppendorf, Hamburg, Germany; wolschke@uke.de

3 Medizinische Klinik 5, Klinikum Nürnberg Nord, Paracelsus Medizinische Privatuniversität, 90419 Nürnberg, Germany; kerstin.schaefer-eckart@klinikum-nuernberg.de (K.S.-E.);

check for updates

Citation: Wagner-Drouet, E.; Teschner, D.; Wolschke, C.; Schäfer-Eckart, K.; Gärtner, J.; Mielke, S.; Schreder, M.; Kobbe, G.; Hilgendorf, I.; Klein, S.; et al. Comparison of CytomegalovirusSpecific Immune Cell Response to Proteins versus Peptides Using an IFN- $\gamma$ ELISpot Assay after Hematopoietic Stem Cell Transplantation. Diagnostics 2021, 11, 312. https://doi.org/10.3390/ diagnostics11020312

Academic Editor: Eric Deconinck

Received: 17 December 2020

Accepted: 12 February 2021

Published: 15 February 2021

Publisher's Note: MDPI stays neutral with regard to jurisdictional claims in published maps and institutional affiliations.

Copyright: (c) 2021 by the authors. Licensee MDPI, Basel, Switzerland. This article is an open access article distributed under the terms and conditions of the Creative Commons Attribution (CC BY) license (https:/ / creativecommons.org/licenses/by/ $4.0 /)$. johannes.gaertner@klinikum-nuernberg.de (J.G.)

4 Department of Medicine II, University Medical Center Würzburg, 97080 Würzburg, Germany; stephan.mielke@ki.se (S.M.); martin.schreder@wienkav.at (M.S.)

5 Department of Laboratory Medicine, CAST, Karolinska Institutet and University Hospital, 17177 Stockholm, Sweden

6 Department of Hematology, University Hospital Düsseldorf, Medical Faculty, Heinrich Heine University, 40225 Düsseldorf, Germany; Kobbe@med.uni-duesseldorf.de

7 Klinik für Innere Medizin II, Abteilung für Hämatologie und Internistische Onkologie, Universitätsklinikum Jena, 07747 Jena, Germany; Inken.Hilgendorf@med.uni-jena.de

8 Department of Hematology and Oncology, UMM University Medical Center Mannheim, University of Heidelberg, 68167 Mannheim, Germany; stefan.klein@umm.de

9 Medical Department, Hematology and Oncology, Klinikum rechts der Isar, Technical University Munich, 81675 Munich, Germany; mareike.verbeek@mri.tum.de

10 Innere Klinik, Tumorforschung, University Hospital Essen, 45147 Essen, Germany; markus.ditschkowski@uk-essen.de

11 Department of Hepatobiliary Surgery and Transplantation, University Medical Center Hamburg-Eppendorf, 20246 Eppendorf, Hamburg, Germany; martina.Koch@unimedizin-mainz.de

12 Institute for Transfusion Medicine, University Hospital Essen, 45147 Essen, Germany; monika.lindemann@uk-essen.de

13 Lophius Biosciences, 93053 Regensburg, Germany; traudel.schmidt@lophius.com (T.S.); anne.rascle@lophius.com (A.R.); sascha.barabas@lophius.com (S.B.); ludwig.deml@lophius.com (L.D.)

14 Institute of Clinical Microbiology and Hygiene, University Medical Center Regensburg, 93053 Regensburg, Germany

15 Department of Internal Medicine III, Hematology and Oncology, University Medical Center Regensburg, 93053 Regensburg, Germany

* Correspondence: ralf.wagner@ukr.de (R.W.); daniel.wolff@ukr.de (D.W.); Tel.: +49-941-944-6452 (R.W.); +49-941-944-5542 (D.W.)

+ Current address: First Department of Medicine, Center for Oncology and Hematology, Wilhelminenspital, 1160 Vienna, Austria.

$\ddagger$ Current address: Department of General-, Visceral- and Transplantation Surgery, University Medical Center of the Johannes Gutenberg University, 55131 Mainz, Germany.

Abstract: Cytomegalovirus (CMV) infection is a major cause of morbidity and mortality following hematopoietic stem cell transplantation (HSCT). Measuring CMV-specific cellular immunity may improve the risk stratification and management of patients. IFN- $\gamma$ ELISpot assays, based on the stimulation of peripheral blood mononuclear cells with CMV pp65 and IE-1 proteins or peptides, have been validated in clinical settings. However, it remains unclear to which extend the T-cell response to synthetic peptides reflect that mediated by full-length proteins processed by antigen-presenting cells. We compared the stimulating ability of pp65 and IE-1 proteins and corresponding overlapping 
peptides in 16 HSCT recipients using a standardized IFN- $\gamma$ ELISpot assay. Paired qualitative test results showed an overall $74.4 \%$ concordance. Discordant results were mainly due to low-response tests, with one exception. One patient with early CMV reactivation and graft-versus-host disease, sustained CMV DNAemia and high $\mathrm{CD}^{+}$counts showed successive negative protein-based ELISpot results but a high and sustained response to IE-1 peptides. Our results suggest that the response to exogenous proteins, which involves their uptake and processing by antigen-presenting cells, more closely reflects the physiological response to CMV infection, while the response to exogenous peptides may lead to artificial in vitro T-cell responses, especially in strongly immunosuppressed patients.

Keywords: CMV; CMV-specific cellular immunity; hematopoietic stem cell transplantation; recall antigen; peptide; immune monitoring; IFN- $\gamma$ ELISpot; $T$ cells; antigen processing and presentation; immunosuppression

\section{Introduction}

Cytomegalovirus (CMV) infection is a serious cause of morbidity and mortality after allogeneic hematopoietic stem cell transplantation (HSCT) [1]. We and others have proposed that measuring CMV-specific cellular immunity might help identify patients at risk for CMV infection and reactivation following HSCT [2-9]. Existing CMV-specific immune monitoring assays are based on the quantification of the number and/or functionality of CMV-specific immune cells using various detection technologies: flow cytometry (following intracellular or tetramer staining), enzyme-linked immunosorbent assay (ELISA) or enzyme-linked immunospot (ELISpot) [10-12]. Two standardized CMV-specific IFN- $\gamma$ ELISpot assays, based on the in vitro stimulation of peripheral blood mononuclear cells

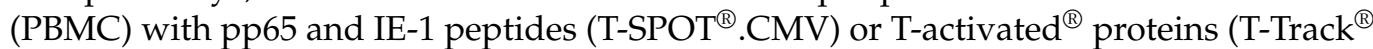
$\mathrm{CMV}$ ), recently demonstrated their suitability to measure CMV-specific cellular immunity in clinical settings $[4,5,8,9,13-18]$.

To act as stimulant, exogenous proteins must be internalized and processed by antigenpresenting cells (APC; mainly dendritic cells and monocytes/macrophages). Internalized proteins are degraded into peptides within endosomes and associate with free major histocompatibility complex (MHC) class II and MHC class I (cross-presentation) molecules in the late endosomal compartment. Peptide-loaded MHC class I and II molecules are transported to the plasma membrane and presented to $\mathrm{CD}^{+}$and $\mathrm{CD} 4^{+} \mathrm{T}$ cells, respectively $[19,20]$. Epitope-specific T cells are then activated, leading to IFN- $\gamma$ secretion [12]. Exogenous peptides are also taken up by APC and intracellularly loaded to de novo-synthesized MHC molecules before being transported to the cell surface and presented to T cells. In addition, exogenous peptides can be directly loaded to free MHC class I molecules present at the plasma membrane. High-affinity peptides can even compete with and replace peptides in preloaded MHC class I molecules at the cell surface. On the other hand, direct loading of peptides onto MHC class II molecules at the cell surface is unlikely to occur, due to the high stability of peptide-bound MHC class II complexes [19,21,22].

One might anticipate that these differences in antigen presentation may have an impact on the stimulating capability of CMV proteins and peptides, and thus on CMV-specific IFN- $\gamma$ ELISpot test results. A recent study using intracellular cytokine staining and flow cytometry directly compared the ability of T-activated ${ }^{\circledR}$ proteins and corresponding overlapping peptide pools to activate $\mathrm{CD}^{+}$and $\mathrm{CD}^{+} \mathrm{T}$ cells in healthy donors. Interestingly, T-activated ${ }^{\circledR}$ proteins and peptides induced comparable CD4 ${ }^{+}$T-cell responses but significantly distinct $\mathrm{CD}^{+} \mathrm{T}$-cell responses [23]. The questions remain as to how these differences in T-cell responses translate in a clinical setting, notably in immunocompromised patients with potentially impaired antigen processing, and how they influence CMV-specific IFN- $\gamma$ ELISpot test results.

The present study directly compared the ability of CMV pp65 and IE-1 proteins and respective 15-mer overlapping peptides to induce the in vitro response of isolated PBMC of 
16 HSCT recipients using a standardized CMV-specific IFN- $\gamma$ ELISpot assay. The ELISpot results were interpreted in the context of the patient's overall clinical picture and of total $\mathrm{CD}^{+} \mathrm{T}$ cell count.

Paired qualitative protein- and peptide-based test results were overall $74.4 \%$ concordant. However, one patient with early and sustained CMV reactivation and high CD8 ${ }^{+}$ counts showed successive negative ELISpot results in response to CMV proteins but a high and sustained response to IE-1 peptides. These observations suggest that in some cases the response to exogenous peptides may lead to artificial in vitro T-cell responses, while the response to exogenous proteins, via their uptake and processing by antigen-presenting cells, more closely reflects the physiological response to CMV infection, especially in patients under intense immunosuppressive therapy.

\section{Materials and Methods}

\subsection{Study Design and Participants}

This study was performed as part of the registered and reported AlloProtectCMV study (clinicaltrials.gov identifier: NCT02156479; [4]). Spare peripheral blood mononuclear cells (PBMC) were used to conduct additional T-cell-based assays for research purposes only, in accordance with the study protocol. Study design, inclusion and exclusion criteria, and treatment regimen have been described elsewhere [4]. This study was approved by the respective ethics committees (DIMDI's registration number 00008544; University of Regensburg's approval number 13-122-0282, 28 February 2014) and all subjects gave written informed consent in accordance with the Declaration of Helsinki, as previously reported [4]. This investigation aimed to compare the response of isolated PBMC to cytomegalovirus (CMV) antigens used as either proteins or peptides in an IFN- $\gamma$ ELISpot assay. CMV-specific cellular immunity was evaluated in the context of $\mathrm{CD}^{+} \mathrm{T}$ cell count, as other immune parameter, and of the overall clinical picture of individual patients, including CMV viral load, occurrence of CMV reactivation, CMV disease and graft-versus-host disease (GvHD). Sixteen intermediate- and high-risk $(\mathrm{D}+/ \mathrm{R}+, \mathrm{D}+/ \mathrm{R}-, \mathrm{D}-/ \mathrm{R}+)$ allogeneic HSCT recipients were included in this study. One to five IFN- $\gamma$ ELISpot assays were conducted per patient and 49 ELISpot tests were performed in total.

\subsection{Viral Load Measurement}

CMV load was measured by quantitative PCR, as described [4]. CMV reactivation was defined as CMV viral load requiring antiviral treatment according to center-specific guidelines and/or physician's decision [4].

\subsection{IFN- $\gamma$ ELISpot Assays}

Blood collection, PBMC isolation and T-Track ${ }^{\circledR}$ CMV assays (Lophius Biosciences $\mathrm{GmbH}$, Regensburg, Germany) were performed and interpreted as previously described [4]. Spot-forming cells (SFC) were normalized to 200,000 PBMC and evaluated on the basis of square-root transformation (sqrt-SFC). Briefly, a test was considered positive if the mean of four replicate sqrt-SFC for 200,000 PBMC (SRM) resulting from pp65 and/or IE-1 stimulation was $\geq \operatorname{sqrt}(10)$ and if the difference of the mean of sqrt-SFC of the stimulated condition to that of the unstimulated condition (SRM[stimulated]-SRM[unstimulated]) was $\geq 0.742$. SRM SFC values from unstimulated conditions were subtracted from those of the antigen-stimulated conditions. For a better display of pp65- and IE-1-specific SFC levels, SRM SFC values are presented as squared $\left(\mathrm{SRM}^{2}\right)$ SFC values (i.e., as "spot countequivalent"), and in a $\log 10$ scale. SRM ${ }^{2}$ SFC values are depicted as scattered plots showing median values (horizontal line), as before [4]. Peptide-based ELISpot assays were interpreted using the same approach and rules as the protein-based T-Track ${ }^{\circledR}$ CMV assays.

\subsection{Antigens}

T-activated ${ }^{\circledR}$ CMV proteins pp65 (amino acids 366-546, hCMV strain AD169) and full length IE-1 (amino acids 1-491, hCMV Towne strain) are part of the T-Track ${ }^{\circledR}$ CMV 
kit, as already described [12]. Peptide pools covering the respective pp65 (366-546) and IE-1 (1-491) regions were ordered from peptides\&elephants (Hennigsdorf, Germany) as 15-mers overlapping by 11 amino acids. Accordingly, the respective peptide pools included 44 (pp65) and 120 (IE-1) peptides. Comparable pp65- and IE-1-specific libraries of 15-mer peptides with an 11 amino acid overlap have been widely described in the literature to study the response of $\mathrm{CMV}$-specific $\mathrm{CD} 4^{+}$and $\mathrm{CD} 8^{+} \mathrm{T}$ cells [24-26]. Peptide pools were reconstituted in DMSO and used at a final concentration of $1 \mu \mathrm{g} / \mathrm{mL} /$ peptide (pp65) and $10 \mu \mathrm{g} / \mathrm{mL} /$ peptide (IE- 1$)$ per stimulation $\left(19 \mathrm{~h}\right.$ at $37^{\circ} \mathrm{C}$ ), based on titration experiments (Figure S1). The final DMSO concentration in stimulation experiments did not exceed $0.2 \%$, and did not induce a non-specific response (Figure S1). Moreover, an independent experiment demonstrated a viability of PBMC after $19 \mathrm{~h}$ stimulation at $37^{\circ} \mathrm{C}>93 \%$ and no DMSO-associated toxicity (not shown), in agreement with published data [27]. Preliminary flow cytometry experiments indicated that pp65 and IE-1 proteins and peptides both activated IFN- $\gamma$-producing $\mathrm{CD} 4^{+}$and $\mathrm{CD} 8^{+} \mathrm{T}$ cells (not shown), in line with recently published results [23].

\subsection{Total $C D 8^{+} T$ Cell Count Determination}

Total CD8 $8^{+}$cells were enumerated by flow cytometry from the same PBMC, and absolute cell counts were calculated using the peripheral blood absolute lymphocyte count determined at the same visit, as previously described [4].

\subsection{Statistical Analysis}

Differences in pp65- and IE-1-specific SFC distributions between ELISpot tests performed using either T-activated ${ }^{\circledR}$ proteins or overlapping peptides were tested using the Mann-Whitney U (MWU) test. Two-sided $p$-values $<0.05$ were considered statistically significant. Due to (i) the existence of multiple measurements per patient (in 9/15 patients), (ii) the heterogeneity of the number of measurements per patient (one ELISpot assay in six patients and two to five ELISpot assays in nine patients), and (iii) the low case number (15 patients included in the final analysis), no statistical tests were applied to compare test agreement in response to proteins vs. peptides. This study aimed at comparing the response to proteins and peptides to identify and characterize potential discordant test results in the context of the overall clinical picture.

\section{Results}

\subsection{Patient Characteristics}

Sixteen HSCT patients were included in this study. A total of 49 ELISpot assays were performed, applying pp65 and IE-1 proteins and peptide pools in parallel for PBMC stimulation. Ten ELISpot assays were excluded from the analysis due to missing data in at least one of the stimulating conditions (Figure 1).

Thirty-nine valid paired ELISpot measurements in 15 patients (one to five tests per patient) were included in the final analysis. Patient characteristics are shown in Table 1. All collected parameters are shown in Table S1.

Table 1. Patient characteristics.

\begin{tabular}{cc}
\hline Study Population, $\boldsymbol{n} \mathbf{( \% )}$ & $\mathbf{1 5 ( \mathbf { 1 0 0 } \% )}$ \\
\hline Gender, $\boldsymbol{n}(\boldsymbol{\%})$ & $8(53.3 \%)$ \\
\hline Male & $7(46.7 \%)$ \\
\hline Female & $57(29-70)$ \\
\hline Age in years, median (range) & $10(66.7 \%)$ \\
\hline Underlying disease, $n(\%)$ & $2(13.3 \%)$ \\
\hline Acute myeloid leukemia &
\end{tabular}


Table 1. Cont.

\begin{tabular}{|c|c|}
\hline Study Population, $n(\%)$ & $15(100 \%)$ \\
\hline Non-Hodgkin's lymphoma & $2(13.3 \%)$ \\
\hline Severe aplastic anemia & $1(6.7 \%)$ \\
\hline \multicolumn{2}{|l|}{ Donor (D)/Recipient (R) CMV serostatus, $n(\%)$} \\
\hline $\mathrm{D}+/ \mathrm{R}+$ & $4(26.7 \%)$ \\
\hline $\mathrm{D}+/ \mathrm{R}-$ & $1(6.6 \%)$ \\
\hline $\mathrm{D}-/ \mathrm{R}+$ & $10(66.7 \%)$ \\
\hline \multicolumn{2}{|l|}{ Stem cell source, $n(\%)$} \\
\hline Bone marrow & $3(20.0 \%)$ \\
\hline Peripheral blood & $12(80.0 \%)$ \\
\hline \multicolumn{2}{|l|}{ Donor source, $n(\%)$} \\
\hline Matched sibling & $4(26.7 \%)$ \\
\hline Matched unrelated donor & $9(60.0 \%)$ \\
\hline Mismatched unrelated donor & $2(13.3 \%)$ \\
\hline \multicolumn{2}{|l|}{ Conditioning regimen, $n(\%)$} \\
\hline Non-myeloablative & $3(20.0 \%)$ \\
\hline Myeloablative, standard (MAC) & $9(60.0 \%)$ \\
\hline Myeloablative, toxicity-reduced (RIC) & $3(20.0 \%)$ \\
\hline At least one treatment-requiring CMV reactivation, $n(\%)$ & $10(66.7 \%)$ \\
\hline CMV disease, $n(\%)$ & $1(6.7 \%)$ \\
\hline Graft-versus-host disease (GvHD), $n(\%)$ & $6(40.0 \%)$ \\
\hline Death, $n(\%)$ & $2(13.3 \%)$ \\
\hline
\end{tabular}

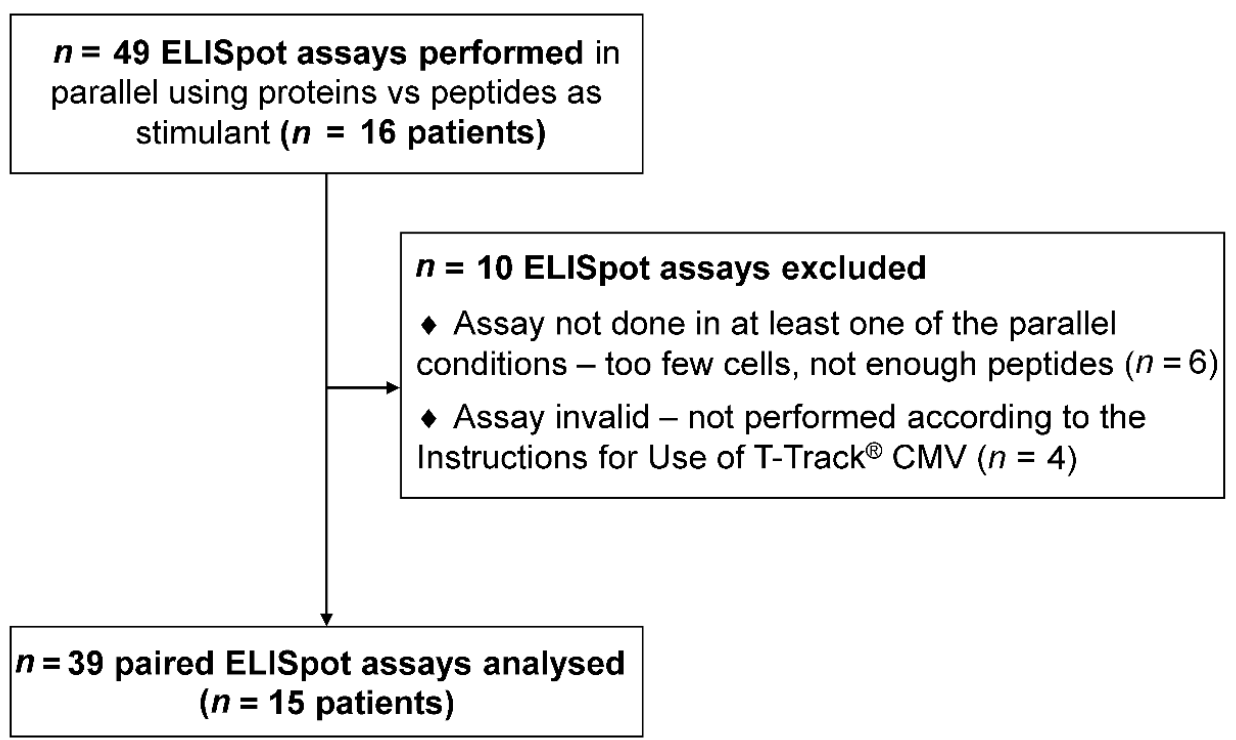

Figure 1. Study flow diagram. Sixteen patients were included in this study. One to five enzymelinked immunospot (ELISpot) assays were conducted per patient, using pp65 and IE-1 proteins and peptide pools in parallel for PBMC stimulation. A total of 49 ELISpot assays were performed. Ten ELISpot assays were excluded from the analysis due to missing data in at least one of the stimulating conditions. Thirty-nine valid paired ELISpot measurements (15 patients) were included in the final analysis (Table 1). 


\subsection{Measurement of CMV-Specific Cellular Immunity in Response to CMV Proteins and Peptides}

CMV-specific cell-mediated immunity was evaluated using a standardized IFN- $\gamma$ ELISpot-based assay (T-Track ${ }^{\circledR} \mathrm{CMV}$ ), which employs urea-formulated (T-activated ${ }^{\circledR}$ ) pp65 and IE-1 proteins as stimulant $[4,12-14,22]$. PBMC were stimulated in parallel with pp65 and IE-1 15-mer peptides covering the same amino acid regions, respectively, and analyzed using the same ELISpot assay procedure and reagents.

The overall spot-forming cells (SFC) distribution was comparable in response to pp65 proteins and peptides (MWU-test $p=0.339$ ), while the response to IE- 1 was significantly higher in response to peptides (MWU-test $p=0.001$ ) (Figure 2a). The analysis of the paired quantitative results showed the same trend (Figure $2 b$ ).

The analysis of the paired qualitative (positive/negative) test results revealed that $35 / 39(89.7 \%)$ and $26 / 39(66.7 \%)$ tests were concordant in response to pp65 and IE-1, respectively (Figure 2b, black circles; Table 2). The proportion of concordant overall ELISpot test results (accounting for both pp65 and IE-1 response, according to the manufacturer's instructions) was $74.4 \%$ (29/39; Table 2).

Table 2. Concordance of qualitative ELISpot test results following stimulation of PBMC with CMV proteins or peptides $(n=39)$.

\begin{tabular}{ccccc}
\hline Results & $\begin{array}{c}\text { Positive } \\
\text { Concordance }\end{array}$ & $\begin{array}{c}\text { Negative } \\
\text { Concordance }\end{array}$ & \multicolumn{2}{c}{ Overall Concordance } \\
\hline & $n$ & $n$ & $n$ & $\%$ \\
\hline $\begin{array}{c}\text { Overall ELISpot test } \\
\text { Result }^{a}\end{array}$ & 16 & 13 & 29 & $74.4 \%(29 / 39)$ \\
\hline IE-1 & 7 & 19 & 26 & $66.7 \%(26 / 39)$ \\
\hline pp65 & 13 & 22 & 35 & $89.7 \%(35 / 39)$ \\
\hline $\begin{array}{l}\text { Test is positive when at least one of the IE-1- and/or pp65-specific response is positive; test is negative when } \\
\text { both IE-1- and pp65-specific responses are negative. }\end{array}$
\end{tabular}

A detailed evaluation of concordant and discordant positive and negative test results is shown in Figure 3 (green and red fields, respectively). The evaluation of the discordant qualitative test results revealed four and 13 discordant pp65- and IE-1-specific test results, respectively (Figure 2b, open circles; Figure 3, red fields; Table S1, greyed fields). The four discordant pp65 test results (positive in response to proteins and negative in response to peptides) showed low spot counts (SFC [SRM $\left.{ }^{2}\right] / 200,000$ PBMC ranging from 0.31 to 16.1 ; Table S1, patients no. 10, 11 and 15), hence close to the limit of quantitation (LoQ) of the ELISpot assay. These four tests were therefore not considered as truly discordant. Six out the 13 discordant IE- 1 test results showed a similar pattern of low spot counts near the LoQ $\left(\mathrm{SFC}\left[\mathrm{SRM}^{2}\right] / 200,000\right.$ PBMC ranging from 0.00 to 23.2; Table S1, patients no. 2, 3, 8, 11 and 14), therefore not truly discordant either. Out of the remaining seven discordant IE-1 tests, four were positive for both pp65 proteins and peptides (Table S1, patients no. 5, 8 and 13), thus resulting in an overall positive (concordant) ELISpot test. In these four cases, the IE-1 discordance had therefore no impact on the final test result (overall positive and concordant between proteins and peptides). The remaining three discordant tests belonged to one patient (no. 12). The response to IE-1 protein was negative (SFC $\left[\mathrm{SRM}^{2}\right] / 200,000$ PBMC ranging from 0.25 to 1.55 ; Table S1) while that to IE-1 peptides was positive and showed high spot counts (SFC [SRM $\left.{ }^{2}\right] / 200,000$ PBMC ranging from 75.3 to 514.4; Table S1). The response to pp65 protein and peptides was negative in all cases (SFC [SRM $\left.{ }^{2}\right] / 200,000$ PBMC ranging from 0.00 to 0.42 ; Table S1). These truly discordant test results in a single patient were investigated in more detail. 


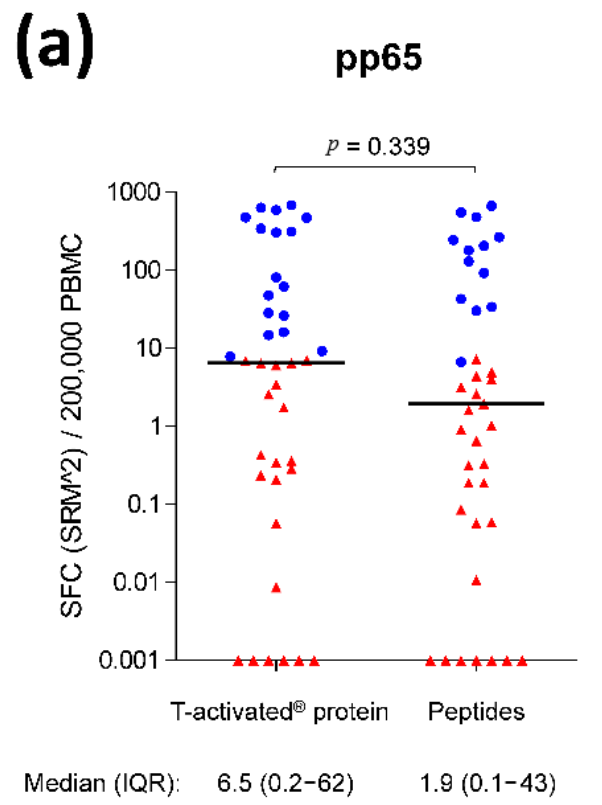

(b)

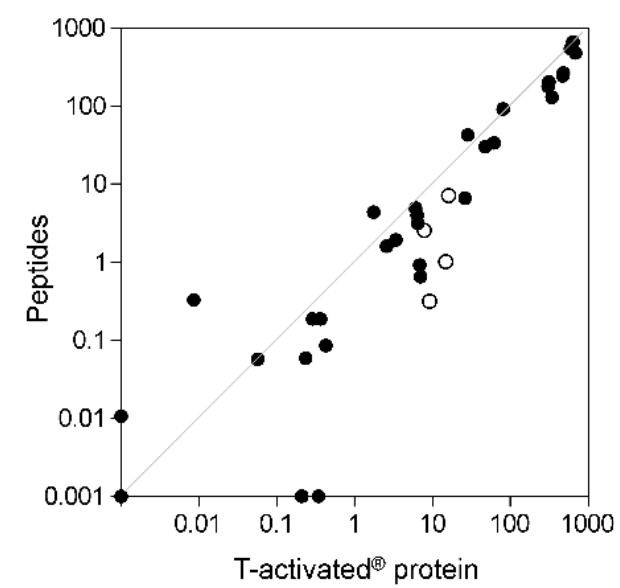

IE-1

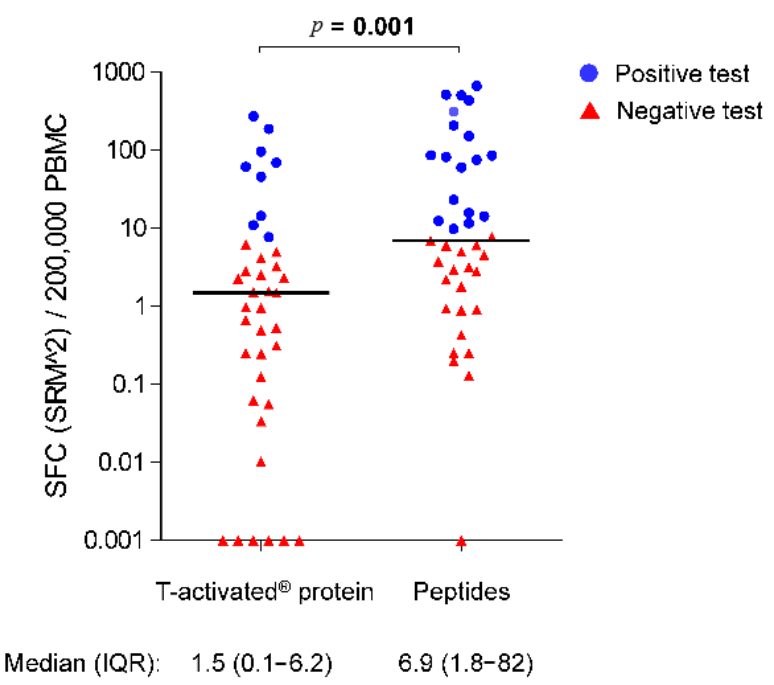

IE-1

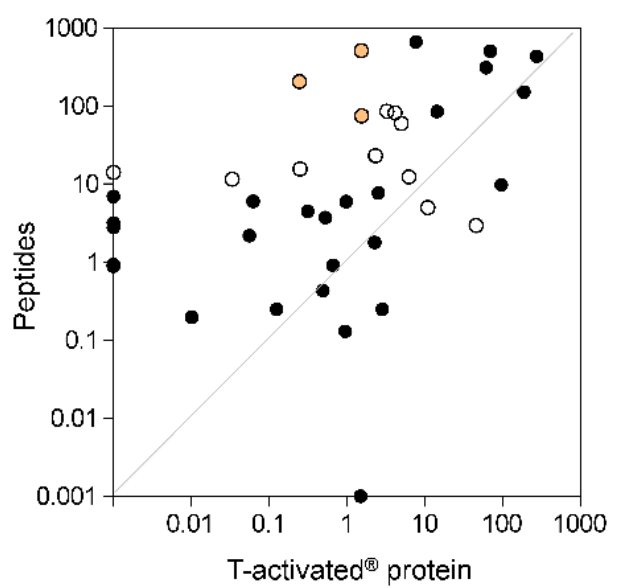

Figure 2. CMV-specific cell-mediated immunity in response to pp65 and IE-1 T-activated ${ }^{\circledR}$ proteins and respective overlapping peptides. (a) Quantitative IFN- $\gamma$ ELISpot results in response to CMV T-activated ${ }^{\circledR}$ proteins pp65 and IE-1 and to the respective overlapping peptides (normalized to 200,000 PBMC) were evaluated on the basis of the mean of squareroot-transformed (SRM) spot-forming cells (SFC), as previously described [4]. Differences in SFC distribution in response to proteins and peptides were evaluated using a Mann-Whitney-U test. Statistically significant $p$-values are shown in bold above each graph. For the sake of simplicity, scatter plots are depicted as squared SRM values (SRM $\left.{ }^{2}\right)$. Median and interquartile range (IQR) of SRM ${ }^{2}$ SFC are shown under each graph. Due to the log scale representation, values of zero $\mathrm{SRM}^{2}$ were replaced by 0.001 ( $y$-axis), meaning that baseline values shown at $y=0.001$ are actually equal to zero. Red triangles and blue dots depict negative and positive tests, respectively, defined according to the rules described in the Methods section and previously reported [4]. (b) Paired quantitative IFN- $\gamma$ ELISpot results in response to T-activated ${ }^{\circledR}$ proteins versus peptides. The antigen-specific ELISpot results shown in panel (a) are represented as paired data. Black circles depict overall concordance (positive and negative concordance; Table 2) and white circles depict discordant results (Figure 3). Orange-filled circles indicate the highly-discordant test results observed in response to IE-1 proteins and peptides in patient no. 12 (Figure 4). 


\begin{tabular}{|c|c|c|c|c|c|c|c|c|c|}
\hline & & & \multicolumn{6}{|c|}{ T-activated ${ }^{\otimes} \mid \mathrm{E}-1$ and $\mathrm{pp} 65$ proteins } & \multirow{3}{*}{$\begin{array}{c}\text { Total, } \\
n\end{array}$} \\
\hline & & & \multicolumn{2}{|c|}{$\begin{array}{l}\text { Overall ELISpot } \\
\text { test result }\end{array}$} & \multicolumn{2}{|c|}{$\mathrm{IE}-1$} & \multicolumn{2}{|c|}{ pp65 } & \\
\hline & & & Positive & Negative & Positive & Negative & Positive & Negative & \\
\hline \multirow{6}{*}{ 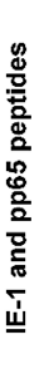 } & \multirow{2}{*}{$\begin{array}{l}\text { Overall } \\
\text { ELISpot } \\
\text { test result }\end{array}$} & Positive & 16 & 7 & & & & & 23 \\
\hline & & Negative & 3 & 13 & & & & & 16 \\
\hline & \multirow{2}{*}{ IE-1 } & Positive & & & 7 & 11 & & & 18 \\
\hline & & Negative & & & 2 & 19 & & & 21 \\
\hline & \multirow{2}{*}{ pp65 } & Positive & & & & & 13 & 0 & 13 \\
\hline & & Negative & & & & & 4 & 22 & 26 \\
\hline & \multicolumn{2}{|l|}{ Total, $\boldsymbol{n}$} & 19 & 20 & 9 & 30 & 17 & 22 & 39 \\
\hline
\end{tabular}

Figure 3. Concordance and discordance of qualitative ELISpot test results following stimulation of PBMC with CMV proteins or peptides $(n=39)$. Qualitative IFN- $\gamma$ ELISpot results in response to CMV T-activated ${ }^{\circledR}$ proteins pp65 and IE-1 and to the respective overlapping peptides (normalized to 200,000 PBMC) were evaluated on the basis of the mean of square-root-transformed (SRM) spot-forming cells (SFC), as previously described [4]. Overall ELISpot test results were interpreted as positive when at least one of the IE-1- and/or pp65-specific response was positive, and as negative when both IE-1 and pp65-specific responses were negative. The number of concordant tests (either positive or negative with both tests) is highlighted in green, while the number of discordant tests (positive/negative) between protein- and peptide-based ELISpot assays is highlighted in red.

\subsection{Monitoring of Immune Parameters and Clinical Complications in Patient No. 12}

The five available IFN- $\gamma$ ELISpot measurements for patient no. 12 (day 41 to 153 post HSCT) were evaluated in parallel to the respective total CD8 ${ }^{+} \mathrm{T}$ cell count, as well as to the respective CMV viral load and other clinical complications (Figure 4 and Table S1).

Patient no. 12 belonged to the high-risk CMV serology group (D-/R+). CMV disease (encephalitis) was documented at day 28 post HSCT. The patient presented high, sustained CMV DNAemia ranging from 1300 to 28,000 copies/mL blood between day 41 and 111, which dropped below the institutional threshold of 1000 copies /mL at day 139 and 153 (Figure 4b; Table S1). Antiviral therapy was initiated at day 28 and discontinued at day 139 after transplantation (with a 37-day interruption between day 61 and 98 due to druginduced leukopenia). Acute GvHD (grade I) was documented before visit 1 (day 20 to 33 post HSCT) and was treated topically with corticosteroids in addition to the continued cyclosporin prophylaxis. No GvHD was documented thereafter (Table S1) and cyclosporin prophylaxis was discontinued at day 132 after transplantation. Absolute $\mathrm{CD}^{+} \mathrm{T}$ cell counts were available at day 55 to 153 . $\mathrm{CD}^{+} \mathrm{T}$ cell counts drastically increased over time, ranging from 212 to 2065 cells / $\mu$ L blood (Figure 4c and Table S1).

The IFN- $\gamma$ ELISpot response to pp65 protein and respective peptides was negative at all investigated visits (Figure $4 \mathrm{a}$ ). The response to T-activated ${ }^{\circledR}$ IE-1 protein was negative at day 41, 55 and 111 post HSCT, turning positive and increasing afterward, and reaching 69 SFC $\left(\right.$ SRM $\left.^{2}\right) / 200,000$ PBMC at day 153 (Figure 4a and Table S1). In contrast, IE-1-specific response to peptides was positive and high at all investigated visits, ranging from 75 to 667 SFC $\left(\right.$ SRM $\left.^{2}\right) / 200,000$ PBMC (Figure 4a and Table S1). Accordingly, the overall T-Track ${ }^{\circledR}$ CMV test in response to T-activated ${ }^{\circledR}$ proteins was negative at day 41, 55 and 111, during the treated CMV reactivation, and positive at day 139 and 153, after the end of treatment for CMV reactivation. In comparison, the overall ELISpot test in response to peptides was positive at all visits, due to the high spot counts induced by IE-1 peptide stimulation. 
(a)

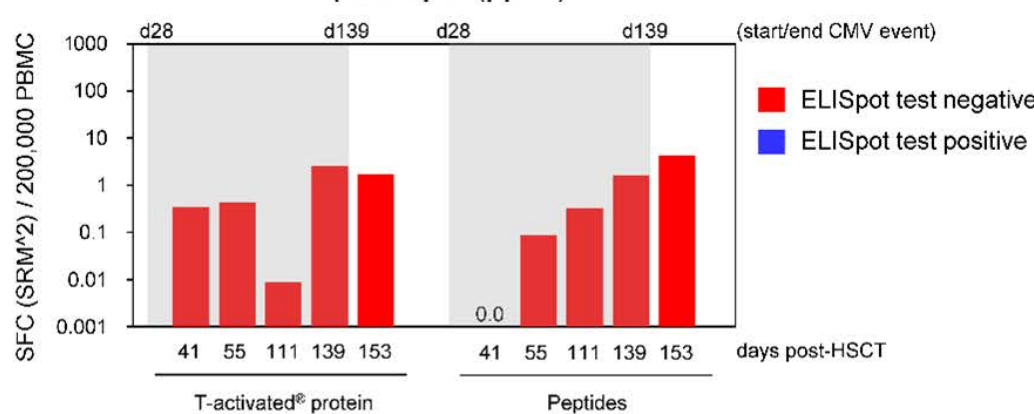

IFN-y ELISpot (IE-1)

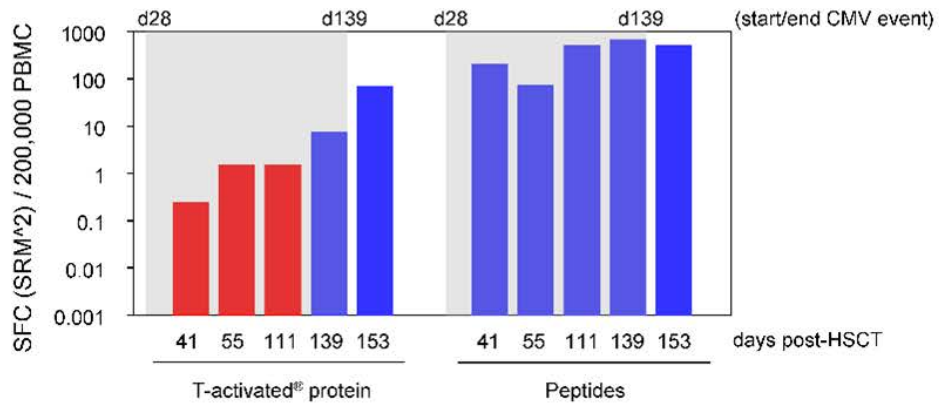

(b)

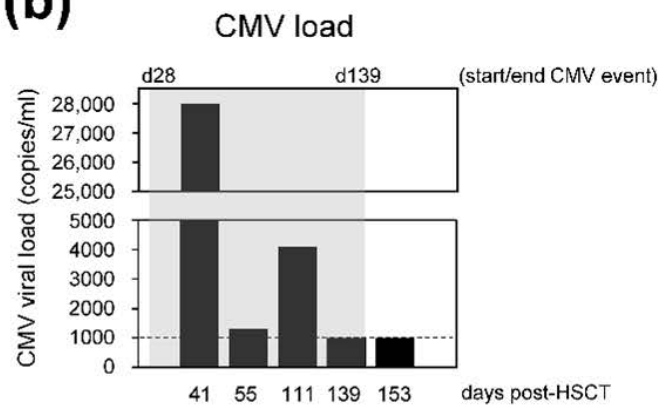

(c)

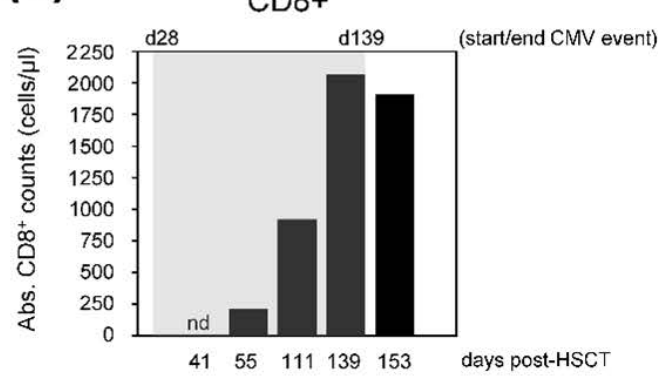

Figure 4. Immune parameters and CMV viral load of HSCT recipient no. 12. Blood of patient no. 12 was withdrawn at day 41, 55, 111, 139 and 153 post-HSCT. (a) PBMC were isolated and analyzed by IFN- $\gamma$ ELISpot using CMV T-activated ${ }^{\circledR}$ proteins or respective overlapping peptides as stimulant. Negative and positive ELISpot test results are represented in red and blue, respectively. ELISpot results were negative at all visits upon stimulation with pp65 T-activated ${ }^{\circledR}$ protein and peptides. Similarly, the response to T-activated ${ }^{\circledR}$ IE-1 protein was low during CMV reactivation (between 0.25 and 8 SFC $\left[\mathrm{SRM}^{2}\right] / 200,000 \mathrm{PBMC}$ ), progressively increasing overtime (up to $69 \mathrm{SFC}\left[\mathrm{SRM}^{2}\right] / 200,000$ PBMC at day 153). In contrast, IE-1-specific response to peptides was high at all investigated visits (75 to $667 \mathrm{SFC}\left[\mathrm{SRM}^{2}\right] / 200,000 \mathrm{PBMC}$ ). (b) CMV viral load (VL), expressed in copies/mL blood, was measured in parallel. CMV VL was above the center-specific threshold for pre-emptive antiviral therapy (dashed line) at day 41 to 111 and returned to the institutional threshold at day 139 and 153. (c) Remaining PBMC were used for the determination of total $\mathrm{CD} 8^{+} \mathrm{T}$ cells by flow cytometry (expressed as total CD8 ${ }^{+} \mathrm{T}$ cells $/ \mu \mathrm{L}$ blood). Flow cytometry was not performed at day 41 (nd, not determined) due to a lack of PBMC. Absolute CD8 ${ }^{+}$ counts were high, ranging from 212 to 2065 cells / $\mu$ L blood at all investigated visits (day 55 to 153). In (a-c), grey shading represents the lengthy CMV event (CMV reactivation requiring antiviral treatment), from day 28 to 139 post-HSCT. Of note, treatment was temporarily interrupted between day 61 and 98 due to drug toxicity. CMV disease was documented at day 28 post-HSCT (i.e., before visit 1/day 41). Acute GvHD (grade I) was also documented before day 41, while no GvHD was documented thereafter (Table S1). Of note, GvHD prophylaxis using the calcineurin inhibitor cyclosporin was discontinued at day 132 post-transplantation.

\section{Discussion}

This study compared the response of PBMC to CMV antigens in a standardized IFN- $\gamma$ ELISpot assay, using either proteins or respective peptides as stimulant. Based on 39 ELISpot assays performed in parallel (including 15 HSCT recipients), the overall test concordance (accounting for both pp65 and IE-1 response) was 74.4\%. Test concordance was stronger in response to pp65 (89.7\%) than to IE-1 $(66.7 \%)$. The lower concordance in response to IE-1 was due to the significantly higher response to peptides vs. proteins, resulting in a higher proportion of positive test results. The higher response to IE-1 peptides might reflect a difference in antigen presentation between proteins and peptides, possibly due to the direct loading of exogenous peptides to MHC class I molecules on the cell surface of APC $[19,21,22]$. That a higher T-cell response was observed using IE-1 but not pp65 
peptides might be due to a higher affinity of IE-1 peptides to the peptide-binding groove of MHC class I molecules [21], although this proposition remains to be demonstrated.

Discordant qualitative (positive/negative) test results in response to proteins vs. peptides were mainly those with very low spot counts and thus close to the LoQ, with one exception. One patient showed repetitively negative T-Track ${ }^{\circledR} \mathrm{CMV}$ tests (in response to T-activated ${ }^{\circledR}$ pp65 and IE-1 proteins) but positive tests with high SFC counts in response to IE-1 (but not pp65) peptides. This patient was characterized by the occurrence of aGvHD and CMV disease early after transplantation, high and sustained CMV DNAemia despite antiviral treatment, and elevated and increasing total $\mathrm{CD} 8^{+}$counts.

The successively negative T-Track ${ }^{\circledR} \mathrm{CMV}$ tests correlated with the high sustained CMV viral load, in line with the expectation that compromised CMV-specific cellular immunity is unable to contain CMV reactivation. Following discontinuation of GvHD prophylaxis at day 132 , the T-Track ${ }^{\circledR} \mathrm{CMV}$ test turned positive (with low spot counts) at day 139, as viral load went down and antiviral treatment was stopped. T-Track ${ }^{\circledR} \mathrm{CMV}$ was then confirmed positive at day 153, with increasing spot counts (69 SFC [SRM $\left.{ }^{2}\right] / 200,000$ $\mathrm{PBMC}$ ), indicating progressive CMV-specific immune reconstitution. This chronology of events also suggests a potential functional interference of cyclosporin with the response to CMV proteins. Altogether, T-Track ${ }^{\circledR}$ CMV test results were in accordance with the patient's clinical picture in terms of risk stratification for CMV complications.

In contrast, the high response to IE-1 peptides at all investigated visits was unexpected. This elevated response might reflect the frequency of reactive $\mathrm{CD} 8^{+} \mathrm{T}$ cells upon presentation by exogenous peptides directly loaded to MHC class I molecules at the cell surface, rather than a physiological immune response, as reported for other viral peptide antigens [28-30]. This proposition is in agreement with the recent demonstration that the stimulation of PBMC of healthy donors with pp65 and IE- 1 overlapping peptides results in a stronger response of $\mathrm{CD}^{+}$(but not $\mathrm{CD}^{+}$) T cells, compared to the stimulation with the respective T-activated ${ }^{\circledR}$ proteins [23]. In line with these observations, patient no. 12 presented increased total $\mathrm{CD} 8^{+} \mathrm{T}$ cell counts. Whether high $\mathrm{CD} 8^{+} \mathrm{T}$ cell counts reflected equally elevated levels of $\mathrm{CMV}$-specific $\mathrm{CD}^{+} \mathrm{T}$ cells in this patient is not known, although absolute $\mathrm{CD} 8^{+} \mathrm{T}$ cell counts usually correlate well with CMV-specific $\mathrm{CD} 8^{+} \mathrm{T}$ cell levels in peripheral blood [11,31-33].

The lack of PBMC responsiveness to pp65 and IE-1 proteins in patient no. 12 cannot be explained by the patient's HLA genotype, since it included several common alleles (e.g., HLA-A*02:01 and HLA-B*07:02) known to bind immunodominant pp65 and IE-1 epitopes [34-36]. Instead, the lack of PBMC responsiveness to pp65 and IE-1 proteins might indicate impaired antigen processing and presentation by APC [22]. Indeed, immunosuppressive agents such as corticosteroids or calcineurin inhibitors are known to interfere with dendritic cells' function [37-39], and patient no. 12 was treated topically with corticosteroids in addition to GvHD prophylaxis with a calcineurin inhibitor at the time CMV disease was diagnosed. Besides, following discontinuation of cyclosporin prophylaxis at day 132, the response to IE-1 protein became positive at day 139 and the number of IE-1-reactive cells in ELISpot further increased at day 153.

Altogether, the overall clinical picture of this patient and the measured immune parameters suggest that the elevated sustained response to IE-1 peptides in the IFN$\gamma$ ELISpot assay indicate the presence of high levels of CMV-specific CD8 ${ }^{+} \mathrm{T}$ cells in peripheral blood, rather than their functionality. In contrast, the lack of response to Tactivated ${ }^{\circledR}$ pp65 and IE-1 proteins in the IFN- $\gamma$ ELISpot assay apparently reflects the lack of in vivo protection, likely due to impaired antigen uptake, processing and presentation. This proposition is further supported by reports of impaired in vivo protection against CMV in HSCT patients with GvHD under intense immunosuppressive therapy, despite the detection of high levels of CMV-specific $\mathrm{CD}^{+} \mathrm{T}$ cells or of in vitro IFN- $\gamma \mathrm{CD} 8^{+}$response to CMV-specific peptides $[40,41]$. 


\section{Conclusions}

This study demonstrated comparable IFN- $\gamma$ ELISpot results in response to pp65 and IE-1 proteins and peptides in most cases (14 out of 15 patients). Yet, some patients, especially those under strong immunosuppressive therapy, might show unreliable in vitro $\mathrm{T}$-cell responses to peptides. In vitro T-cell responses to proteins seem to mimic more closely the natural response to $\mathrm{CMV}$ infection via the antigen uptake, processing and presentation pathway, hence allowing more accurate and reliable risk stratification of patients. This study further demonstrates the suitability of the standardized IFN- $\gamma$ ELISpot assay TTrack ${ }^{\circledR}$ CMV to evaluate CMV-specific cellular immunity in immunocompromised patients, and supports its implementation in clinical routine for an improved risk stratification and management of patients.

Supplementary Materials: The following are available online at https: / / www.mdpi.com/2075-441 8/11/2/312/s1, Table S1: Individual patients' characteristics, and measured immune and CMV viral load parameters. Figure S1. Titration of pp65 and IE-1 peptide pools.

Author Contributions: Conceptualization, L.D., D.W., S.B. and R.W.; methodology, L.D., D.W., R.W., S.B., T.S. and A.R.; validation, S.B., T.S. and A.R.; formal analysis, E.W.-D., M.K., M.L., S.B., T.S. and A.R.; investigation, D.W., E.W.-D., D.T., C.W., K.S.-E., J.G., S.M., M.S., G.K., I.H., S.K., M.V., M.D., M.K., M.L. and S.B.; resources, L.D., R.W., S.B., D.W., E.W.-D., D.T., C.W., K.S.-E., J.G., S.M., M.S., G.K., I.H., S.K., M.V. and M.D.; data curation, D.W., E.W.-D., D.T., C.W., K.S.-E., J.G., S.M., M.S., G.K., I.H., S.K., M.V., M.D. and T.S.; writing—original draft preparation, A.R.; writing-review and editing, A.R., D.W., L.D., T.S., S.B., D.T., K.S.-E., M.L. and R.W.; visualization, A.R.; funding acquisition, D.W. and L.D.; supervision, D.W., T.S., L.D., S.B. and R.W.; project administration, T.S., L.D., S.B. and R.W. All authors have read and agreed to the published version of the manuscript.

Funding: The AlloProtectCMV study was supported in part by the German Federal Ministry of Education and Research (BMBF grant number 031A215) to Lophius Biosciences and by research funding from Lophius Biosciences to D.W., E.W., D.T., C.W., K.S.-E., J.G., S.M., M.S., G.K., I.H., S.K., M.V., M.D., M.K. and M.L., D.W. was supported by the Deutsche Forschungsgemeinschaft (DFG, German Research Foundation, grant number 324392634-TRR 221). The APC was funded by the University of Regensburg.

Institutional Review Board Statement: The AlloProtectCMV study (clinicaltrials.gov identifier: NCT02156479; [4]) was conducted according to the guidelines of the Declaration of Helsinki, and approved by the respective Ethics Committee (DIMDI's registration number 00008544; University of Regensburg's approval number 13-122-0282).

Informed Consent Statement: Informed consent was obtained from all subjects involved in the study.

Data Availability Statement: The data presented in this study are available within the manuscript and Supplementary Material (Table S1).

Acknowledgments: We are grateful to all contributors of the AlloProtectCMV study, in particular study participants, as well as Marie von Lilienfeld-Toal, Dietlinde Janson, Mustafa Kondakci, Daniela Heidenreich, Sebastian Kreil, Sandra Graß, Tanja Gromke, Anja Svenson, Julia Batzilla, Hanna Bendfeldt, Astrid Starke, Harald Guldan and Alcedis GmbH (Giessen, Germany) for their expertise and assistance in data collection, data management, and study planning and coordination. We thank Thomas Keller and Stephan Weber (ACOMED Statistik, Leipzig, Germany) for their statistical support. T-Track ${ }^{\circledR}$ CMV tests were provided by Lophius Biosciences $\mathrm{GmbH}$, Regensburg, Germany.

Conflicts of Interest: The participating clinical and measurement centers (D.W., E.W., D.T., C.W., K.S.-E., J.G., S.M., M.S., G.K., I.H., S.K., M.V., M.D., M.K. and M.L.) received research funding from Lophius Biosciences for this study. L.D. is an employee, co-founder, Chief Scientific Officer and shareholder of Lophius Biosciences. S.B. is an employee and shareholder of Lophius Biosciences. T.S. and A.R. are employees of Lophius Biosciences. R.W. is Chairman of the Board and a shareholder of Lophius Biosciences. Lophius Biosciences played a role in the design of the study, in the analysis and interpretation of data, in the writing of the manuscript, and in the decision to publish the results. 


\section{References}

1. De la Cámara, R. CMV in Hematopoietic Stem Cell Transplantation. Mediterr. J. Hematol. Infect. Dis. 2016, 8, e2016031. [CrossRef]

2. Lilleri, D.; Gerna, G. Strategies to Control Human Cytomegalovirus Infection in Adult Hematopoietic Stem Cell Transplant Recipients. Immunotherapy 2016, 8, 1135-1149. [CrossRef] [PubMed]

3. Ljungman, P.; de la Camara, R.; Robin, C.; Crocchiolo, R.; Einsele, H.; Hill, J.A.; Hubacek, P.; Navarro, D.; Cordonnier, C.; Ward, K.N.; et al. Guidelines for the Management of Cytomegalovirus Infection in Patients with Haematological Malignancies and after Stem Cell Transplantation from the 2017 European Conference on Infections in Leukaemia (ECIL 7). Lancet Infect. Dis. 2019, 19, e260-e272. [CrossRef]

4. Wagner-Drouet, E.; Teschner, D.; Wolschke, C.; Janson, D.; Schäfer-Eckart, K.; Gärtner, J.; Mielke, S.; Schreder, M.; Kobbe, G.; Kondakci, M.; et al. Standardized Monitoring of Cytomegalovirus-Specific Immunity Can Improve Risk Stratification of Recurrent Cytomegalovirus Reactivation after Hematopoietic Stem Cell Transplantation. Haematologica 2021, 106, 363-374. [CrossRef] [PubMed]

5. Nesher, L.; Shah, D.P.; Ariza-Heredia, E.J.; Azzi, J.M.; Siddiqui, H.K.; Ghantoji, S.S.; Marsh, L.Y.; Michailidis, L.; Makedonas, G.; Rezvani, K.; et al. Utility of the Enzyme-Linked Immunospot Interferon- $\gamma$-Release Assay to Predict the Risk of Cytomegalovirus Infection in Hematopoietic Cell Transplant Recipients. J. Infect. Dis. 2016, 213, 1701-1707. [CrossRef]

6. Boeckh, M.; Leisenring, W.; Riddell, S.R.; Bowden, R.A.; Huang, M.-L.; Myerson, D.; Stevens-Ayers, T.; Flowers, M.E.D.; Cunningham, T.; Corey, L. Late Cytomegalovirus Disease and Mortality in Recipients of Allogeneic Hematopoietic Stem Cell Transplants: Importance of Viral Load and T-Cell Immunity. Blood 2003, 101, 407-414. [CrossRef]

7. Avetisyan, G.; Aschan, J.; Hägglund, H.; Ringdén, O.; Ljungman, P. Evaluation of Intervention Strategy Based on CMV-Specific Immune Responses after Allogeneic SCT. Bone Marrow Transplant. 2007, 40, 865-869. [CrossRef]

8. Chemaly, R.F.; El Haddad, L.; Winston, D.J.; Rowley, S.D.; Mulane, K.M.; Chandrasekar, P.; Avery, R.K.; Hari, P.; Peggs, K.S.; Kumar, D.; et al. Cytomegalovirus (CMV) Cell-Mediated Immunity and CMV Infection After Allogeneic Hematopoietic Cell Transplantation: The REACT Study. Clin. Infect. Dis. 2020, 71, 2365-2374. [CrossRef]

9. $\quad$ El Haddad, L.; Ariza-Heredia, E.; Shah, D.P.; Jiang, Y.; Blanchard, T.; Ghantoji, S.S.; El Chaer, F.; El-Haddad, D.; Prayag, A.; Nesher, L.; et al. The Ability of a Cytomegalovirus ELISPOT Assay to Predict Outcome of Low-Level CMV Reactivation in Hematopoietic Cell Transplant Recipients. J. Infect. Dis. 2019, 219, 898-907. [CrossRef]

10. Yong, M.K.; Lewin, S.R.; Manuel, O. Immune Monitoring for CMV in Transplantation. Curr. Infect. Dis. Rep. 2018, 20, 4. [CrossRef]

11. Ciáurriz, M.; Zabalza, A.; Beloki, L.; Mansilla, C.; Pérez-Valderrama, E.; Lachén, M.; Bandrés, E.; Olavarría, E.; Ramírez, N. The Immune Response to Cytomegalovirus in Allogeneic Hematopoietic Stem Cell Transplant Recipients. Cell. Mol. Life Sci. CMLS 2015, 72, 4049-4062. [CrossRef]

12. Barabas, S.; Spindler, T.; Kiener, R.; Tonar, C.; Lugner, T.; Batzilla, J.; Bendfeldt, H.; Rascle, A.; Asbach, B.; Wagner, R.; et al. An Optimized IFN- $\gamma$ ELISpot Assay for the Sensitive and Standardized Monitoring of CMV Protein-Reactive Effector Cells of Cell-Mediated Immunity. BMC Immunol. 2017, 18, 14. [CrossRef]

13. Banas, B.; Steubl, D.; Renders, L.; Chittka, D.; Banas, M.C.; Wekerle, T.; Koch, M.; Witzke, O.; Mühlfeld, A.; Sommerer, C.; et al. Clinical Validation of a Novel ELISpot-Based in Vitro Diagnostic Assay to Monitor CMV-Specific Cell-Mediated Immunity in Kidney Transplant Recipients: A Multicenter, Longitudinal, Prospective, Observational Study. Transpl. Int. 2018, 31, 436-450. [CrossRef] [PubMed]

14. Banas, B.; Böger, C.A.; Lückhoff, G.; Krüger, B.; Barabas, S.; Batzilla, J.; Schemmerer, M.; Köstler, J.; Bendfeldt, H.; Rascle, A.; et al. Validation of T-Track $® C M V$ to Assess the Functionality of Cytomegalovirus-Reactive Cell-Mediated Immunity in Hemodialysis Patients. BMC Immunol. 2017, 18, 15. [CrossRef]

15. Jarque, M.; Crespo, E.; Melilli, E.; Gutiérrez, A.; Moreso, F.; Guirado, L.; Revuelta, I.; Montero, N.; Torras, J.; Riera, L.; et al. Cellular Immunity to Predict the Risk of Cytomegalovirus Infection in Kidney Transplantation: A Prospective, Interventional, Multicenter Clinical Trial. Clin. Infect. Dis. 2020, 71, 2375-2385. [CrossRef] [PubMed]

16. Jarque, M.; Melilli, E.; Crespo, E.; Manonelles, A.; Montero, N.; Torras, J.; Cruzado, J.M.; Luque, S.; Gil-Vernet, S.; Grinyó, J.M.; et al. CMV-Specific Cell-Mediated Immunity at 3-Month Prophylaxis Withdrawal Discriminates D+/R+ Kidney Transplants at Risk of Late-Onset CMV Infection Regardless the Type of Induction Therapy. Transplantation 2018, 102, e472-e480. [CrossRef]

17. Chanouzas, D.; Small, A.; Borrows, R.; Ball, S. Assessment of the T-SPOT.CMV Interferon- $\gamma$ Release Assay in Renal Transplant Recipients: A Single Center Cohort Study. PLoS ONE 2018, 13, e0193968. [CrossRef]

18. Kumar, D.; Chin-Hong, P.; Kayler, L.; Wojciechowski, D.; Limaye, A.P.; Osama Gaber, A.; Ball, S.; Mehta, A.K.; Cooper, M.; Blanchard, T.; et al. A Prospective Multicenter Observational Study of Cell-Mediated Immunity as a Predictor for Cytomegalovirus Infection in Kidney Transplant Recipients. Am. J. Transplant. 2019, 19, 2505-2516. [CrossRef]

19. Neefjes, J.; Jongsma, M.L.M.; Paul, P.; Bakke, O. Towards a Systems Understanding of MHC Class I and MHC Class II Antigen Presentation. Nat. Rev. Immunol. 2011, 11, 823-836. [CrossRef] [PubMed]

20. Colbert, J.D.; Cruz, F.M.; Rock, K.L. Cross-Presentation of Exogenous Antigens on MHC I Molecules. Curr. Opin. Immunol. 2020, 64, 1-8. [CrossRef]

21. Luft, T.; Rizkalla, M.; Tai, T.Y.; Chen, Q.; MacFarlan, R.I.; Davis, I.D.; Maraskovsky, E.; Cebon, J. Exogenous Peptides Presented by Transporter Associated with Antigen Processing (TAP)-Deficient and TAP-Competent Cells: Intracellular Loading and Kinetics of Presentation. J. Immunol. 2001, 167, 2529-2537. [CrossRef] 
22. Barabas, S.; Gary, R.; Bauer, T.; Lindner, J.; Lindner, P.; Weinberger, B.; Jilg, W.; Wolf, H.; Deml, L. Urea-Mediated Cross-Presentation of Soluble Epstein-Barr Virus BZLF1 Protein. PLoS Pathog. 2008, 4, e1000198. [CrossRef]

23. Körber, N.; Behrends, U.; Protzer, U.; Bauer, T. Evaluation of T-Activated Proteins as Recall Antigens to Monitor Epstein-Barr Virus and Human Cytomegalovirus-Specific T Cells in a Clinical Trial Setting. J. Transl. Med. 2020, 18, 242. [CrossRef] [PubMed]

24. Hobeika, A.C.; Morse, M.A.; Osada, T.; Ghanayem, M.; Niedzwiecki, D.; Barrier, R.; Lyerly, H.K.; Clay, T.M. Enumerating Antigen-Specific T-Cell Responses in Peripheral Blood: A Comparison of Peptide MHC Tetramer, ELISpot, and Intracellular Cytokine Analysis. J. Immunother. 2005, 28, 63-72. [CrossRef]

25. Slezak, S.L.; Bettinotti, M.; Selleri, S.; Adams, S.; Marincola, F.M.; Stroncek, D.F. CMV Pp65 and IE-1 T Cell Epitopes Recognized by Healthy Subjects. J. Transl. Med. 2007, 5, 17. [CrossRef]

26. Ameres, S.; Liang, X.; Wiesner, M.; Mautner, J.; Moosmann, A. A Diverse Repertoire of CD4 T Cells Targets the Immediate-Early 1 Protein of Human Cytomegalovirus. Front. Immunol. 2015, 6, 598. [CrossRef]

27. Chevalier, M.F.; Bobisse, S.; Costa-Nunes, C.; Cesson, V.; Jichlinski, P.; Speiser, D.E.; Harari, A.; Coukos, G.; Romero, P.; Nardelli-Haefliger, D.; et al. High-Throughput Monitoring of Human Tumor-Specific T-Cell Responses with Large Peptide Pools. Oncoimmunology 2015, 4, e1029702. [CrossRef] [PubMed]

28. Valentine, L.E.; Piaskowski, S.M.; Rakasz, E.G.; Henry, N.L.; Wilson, N.A.; Watkins, D.I. Recognition of Escape Variants in ELISPOT Does Not Always Predict CD8+ T-Cell Recognition of Simian Immunodeficiency Virus-Infected Cells Expressing the Same Variant Sequences. J. Virol. 2008, 82, 575-581. [CrossRef] [PubMed]

29. Yokomaku, Y.; Miura, H.; Tomiyama, H.; Kawana-Tachikawa, A.; Takiguchi, M.; Kojima, A.; Nagai, Y.; Iwamoto, A.; Matsuda, Z.; Ariyoshi, K. Impaired Processing and Presentation of Cytotoxic-T-Lymphocyte (CTL) Epitopes Are Major Escape Mechanisms from CTL Immune Pressure in Human Immunodeficiency Virus Type 1 Infection. J. Virol. 2004, 78, 1324-1332. [CrossRef] [PubMed]

30. Bennett, M.S.; Ng, H.L.; Dagarag, M.; Ali, A.; Yang, O.O. Epitope-Dependent Avidity Thresholds for Cytotoxic T-Lymphocyte Clearance of Virus-Infected Cells. J. Virol. 2007, 81, 4973-4980. [CrossRef]

31. Hakki, M.; Riddell, S.R.; Storek, J.; Carter, R.A.; Stevens-Ayers, T.; Sudour, P.; White, K.; Corey, L.; Boeckh, M. Immune Reconstitution to Cytomegalovirus after Allogeneic Hematopoietic Stem Cell Transplantation: Impact of Host Factors, Drug Therapy, and Subclinical Reactivation. Blood 2003, 102, 3060-3067. [CrossRef]

32. Ogonek, J.; Varanasi, P.; Luther, S.; Schweier, P.; Kühnau, W.; Göhring, G.; Dammann, E.; Stadler, M.; Ganser, A.; Borchers, S.; et al. Possible Impact of CMV-Specific CD8+ T-Cells on Immune Reconstitution and Conversion to Complete Donor Chimerism after Allogeneic SCT. Biol. Blood Marrow Transplant. 2017, 23, 1046-1053. [CrossRef] [PubMed]

33. Shams El-Din, A.A.; El-Desoukey, N.A.; Amin Tawadrous, D.G.; Fouad, N.M.B.E.-D.; Abdel-Mooti, M.; Hotar, S.F. The Potential Association of CMV-Specific CD8+ T Lymphocyte Reconstitution with the Risk of CMV Reactivation and Persistency in Post Allogeneic Stem Cell Transplant Patients. Hematology 2018, 23, 463-469. [CrossRef]

34. Khan, N.; Cobbold, M.; Keenan, R.; Moss, P.A.H. Comparative Analysis of CD8+ T Cell Responses against Human Cytomegalovirus Proteins Pp65 and Immediate Early 1 Shows Similarities in Precursor Frequency, Oligoclonality, and Phenotype. J. Infect. Dis. 2002, 185, 1025-1034. [CrossRef] [PubMed]

35. Elkington, R.; Walker, S.; Crough, T.; Menzies, M.; Tellam, J.; Bharadwaj, M.; Khanna, R. Ex Vivo Profiling of CD8+-T-Cell Responses to Human Cytomegalovirus Reveals Broad and Multispecific Reactivities in Healthy Virus Carriers. J. Virol. 2003, 77, 5226-5240. [CrossRef]

36. Lacey, S.F.; Villacres, M.C.; La Rosa, C.; Wang, Z.; Longmate, J.; Martinez, J.; Brewer, J.C.; Mekhoubad, S.; Maas, R.; Leedom, J.M.; et al. Relative Dominance of HLA-B*07 Restricted CD8+ T-Lymphocyte Immune Responses to Human Cytomegalovirus Pp65 in Persons Sharing HLA-A*02 and HLA-B*07 Alleles. Hum. Immunol. 2003, 64, 440-452. [CrossRef]

37. Hackstein, H.; Thomson, A.W. Dendritic Cells: Emerging Pharmacological Targets of Immunosuppressive Drugs. Nat. Rev. Immunol. 2004, 4, 24-34. [CrossRef] [PubMed]

38. Woltman, A.M.; de Fijter, J.W.; Kamerling, S.W.; Paul, L.C.; Daha, M.R.; van Kooten, C. The Effect of Calcineurin Inhibitors and Corticosteroids on the Differentiation of Human Dendritic Cells. Eur. J. Immunol. 2000, 30, 1807-1812. [CrossRef]

39. Tajima, K.; Amakawa, R.; Ito, T.; Miyaji, M.; Takebayashi, M.; Fukuhara, S. Immunomodulatory Effects of Cyclosporin A on Human Peripheral Blood Dendritic Cell Subsets. Immunology 2003, 108, 321-328. [CrossRef]

40. Solano, C.; Benet, I.; Remigia, M.J.; de la Cámara, R.; Muñoz-Cobo, B.; Costa, E.; Clari, M.Á.; Bravo, D.; Amat, P.; Navarro, D. Immunological Monitoring for Guidance of Preemptive Antiviral Therapy for Active Cytomegalovirus Infection in Allogeneic Stem-Cell Transplant Recipients: A Pilot Experience. Transplantation 2011, 92, e17-e20. [CrossRef]

41. Ozdemir, E.; St John, L.S.; Gillespie, G.; Rowland-Jones, S.; Champlin, R.E.; Molldrem, J.J.; Komanduri, K.V. Cytomegalovirus Reactivation Following Allogeneic Stem Cell Transplantation Is Associated with the Presence of Dysfunctional Antigen-Specific CD8+ T Cells. Blood 2002, 100, 3690-3697. [CrossRef] [PubMed] 